\title{
Study on the Pollen Thermo-Sensitive and Stigma Exsertion Male Sterile Line Tomato (Lycopersicon esculentum Mill.) cv. Da107
}

\author{
Qinzhi Yu' ${ }^{1}$, Congyao Liang'2, Xianyu Wang3*, Yongcheng Du ${ }^{4}$, \\ Masaharu Masuda5, Kenji Murakami ${ }^{5}$ \\ ${ }^{1}$ Guilin Economic Crops Technology Extending Station, Guilin, China \\ ${ }^{2}$ Nanzhang County Agricultural Technology Promotion Center, Xiangyang, China \\ ${ }^{3}$ Agricultural College, Guangxi University, Nanning, China \\ ${ }^{4}$ Institute of Vegetables and Flowers, Chinese Academy of Agricultural Sciences, Beijing, China \\ ${ }^{5}$ Okayama University, Okayama, Japan \\ Email: fengdi053@163.com, liangcongyao@163.com, ${ }^{*}$ wang12261962@163.com
}

Received 13 January 2015; accepted 9 October 2015; published 12 October 2015

Copyright (C) 2015 by authors and Scientific Research Publishing Inc.

This work is licensed under the Creative Commons Attribution International License (CC BY).

http://creativecommons.org/licenses/by/4.0/

(c) (i) 0pen Access

\section{Abstract}

To accelerate the breeding process, male sterile line is used to leave out the troublesome procedures of the artificial emasculation in tomato breeding. However, the fertility of the pollen thermo-sensitivity male sterile line (PTMSL) and the stigma exsertion male sterile line (SEMSL) are affected easily by the environments when used alone. The trial materials were Da107 and the control was First. This study was conducted to create a new male sterile line of tomato characterized by pollen thermo-sensitivity and long style by genic recombination through the hybridizing of the PTMSL and SEMSL. Research on the statistics of the pollen germination rate, the contamination rate in $F_{1}$ and the flower organics indicated that Da107 was an ideal TS and SE male sterile line with the sterility of $95 \%$, as well as it also could be used as fertile line at low temperature. Meanwhile, the results showed that hybrid-seed contamination risk with selfed seeds from residual fertility in Da107 was low.

\section{Keywords}

Lycopersicon esculentum Mill., Pollen-Thermo-Sensitivity Male Sterility, Stigma-Exsertion Male Sterility, Pollen Germination, Seed Contamination Rate

\footnotetext{
${ }^{*}$ Corresponding author.

How to cite this paper: Yu, Q.Z., Liang, C.Y., Wang, X.Y., Du, Y.C., Masuda, M. and Murakami, K. (2015) Study on the Pollen Thermo-Sensitive and Stigma Exsertion Male Sterile Line Tomato (Lycopersicon esculentum Mill.) cv. Da107. American Journal of Plant Sciences, 6, 2535-2539. http://dx.doi.org/10.4236/ajps.2015.616255
} 


\section{Introduction}

Tomato (Lycopersicon esculentum Mill.) belongs to the Solanaceae and Lycopersicon family, a self-pollinated plant with obvious heterosis. And heterosis breeding is the general method of obtaining high production which depends on the elaboration of effective methods of hybrid seed production [1]. So it is critical to make wide use of male sterility for hybrid seed production [2] and identify genetically stable lines that can be used in hybrid seed-breeding programs [3]. Plant breeders paid great attentions to the male sterility of tomato since the first one was discovered by Crane in 1915, and work had been done one after another [4]. The different temperature grads and time grads, could affect the elongation of exserted-stigma [5], the functional style male sterility line of stigma exsertion tomato could reach $95 \%$ of the infertility rate in the field of more than $20^{\circ} \mathrm{C}$ temperature [6]. And many researches related to select breeding, cytology, physiology and biochemistry have been reported [7] [8]. Although more than $40 \mathrm{~ms}$ genes are known in tomato, most of which are not applicable for a practical hybrid seed production, because of the difficulty in maintaining their pure line by seeds [9]. In this study, we took the high pure hybrid-seed rate for the objection, and tried to take full advantage of male sterile materials.

\section{Materials and Methods}

\subsection{Materials}

This study was carried out under natural conditions at College of Agriculture Experiment Base of Guangxi University in late June. The temperature was between $10^{\circ} \mathrm{C}$ and $30^{\circ} \mathrm{C}$. Experimental plants Da107 used as the test group were derived from successive self-pollination for six generations after the hybridization of T-4 (a genic male sterile line from Okayama University) and stigma exsertion mutant type (WANYU), and the fertile line First was used as the control.

The experimental materials were treated with 3 steps as follow: 1) The seeds were disinfected in water solution with Trisodium phosphate dodecahydrate's concentration of $10 \%$ for 20 minutes; flushed with water; and then soaked in normal temperature water for 12 hours; finally, accelerated germination with gauze in normal temperature, and each day during germination with water washing $1-2$ times. 2) Culture of seedling was in seedling matrix with seedling-raising disk. 3) Transplanted when the seedlings were 25 days old in a glass greenhouse; and other management was according to the normal level. The experimental dates of the tomato trial were tabulated.

\subsection{Method}

\subsubsection{The Statistics of Pollen Germination Rate (PGR)}

The pollens were collected from each flower blooming that day of Da107 and First at anthesis, and marked with Da107 and First (adding different temperature treatments and the date of sampling) respectively, then cultivated with the pollen medium ( $0.005 \mathrm{~g}$ boric acid, $\mathrm{o} . \mathrm{o} 1 \mathrm{~g}$ calcium chloride, $10 \mathrm{~g}$ glucose and xml distilled water per 100 $\mathrm{ml}$ solution) at $25^{\circ} \mathrm{C}$ for $2 \mathrm{~h}$. Finally, the pollen germination rate of 5 eye shots in the microscope was calculated.

\subsubsection{The Study of Floral Organs}

The flowers were gathered from Da107 and First when bloomed completely that day. A ruler was used to measure the length of the styluses and the stamens, as well as the size of the styluses' diameter. And the photos of the typical flowers were taken.

\subsubsection{Investigation of $\mathrm{F}_{1}$ Seed Contamination Rate}

$\mathrm{F}_{1}$ seeds whose female parent was Da107 were sowed in pots. The contamination rate was observed, as the seedlings grew up with three main leaves, characterized by leaf shapes compared with the female parent's.

\section{Results and Discussion}

\subsection{The Pollen Germination Rate and Temperature}

There were no significant difference in the pollen germination rate between Da107 and First grew at night temperature(NT) between $14^{\circ} \mathrm{C}-18^{\circ} \mathrm{C}$ (Figure 1). On the contrary, the results showed significant difference between those grew at $20^{\circ} \mathrm{C}-28^{\circ} \mathrm{C}$ (NT) (Figure 2). The two pictures (as below) indicated that temperature was a 


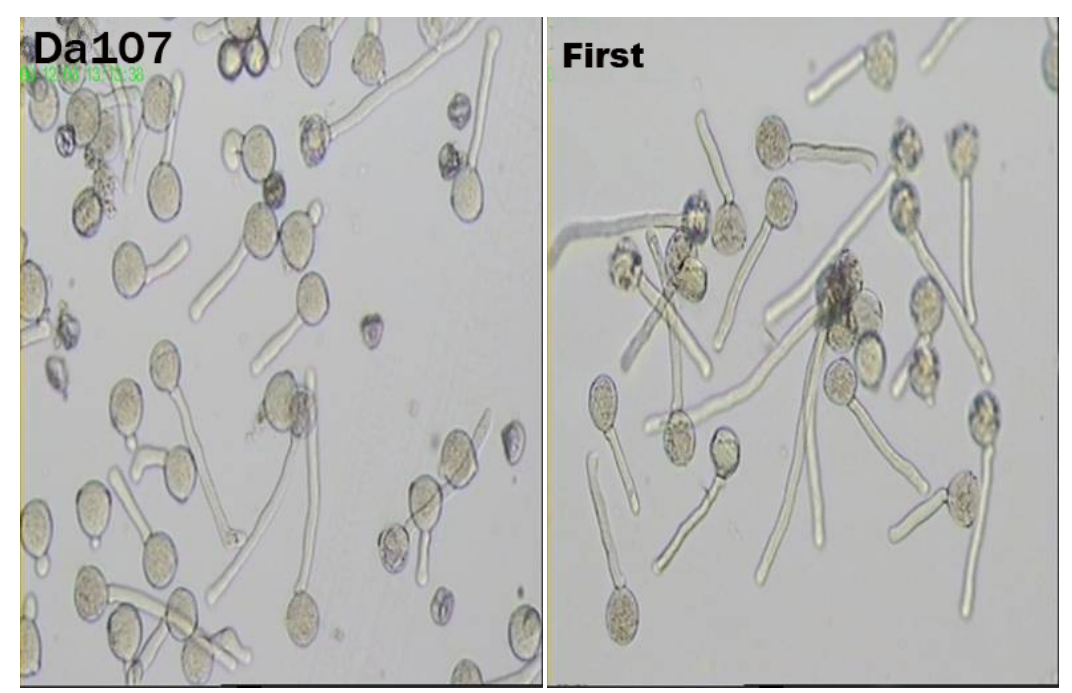

Figure 1. The comparison chart of PGR [grew at $14^{\circ} \mathrm{C}-18^{\circ} \mathrm{C}(\mathrm{NT})$ ].

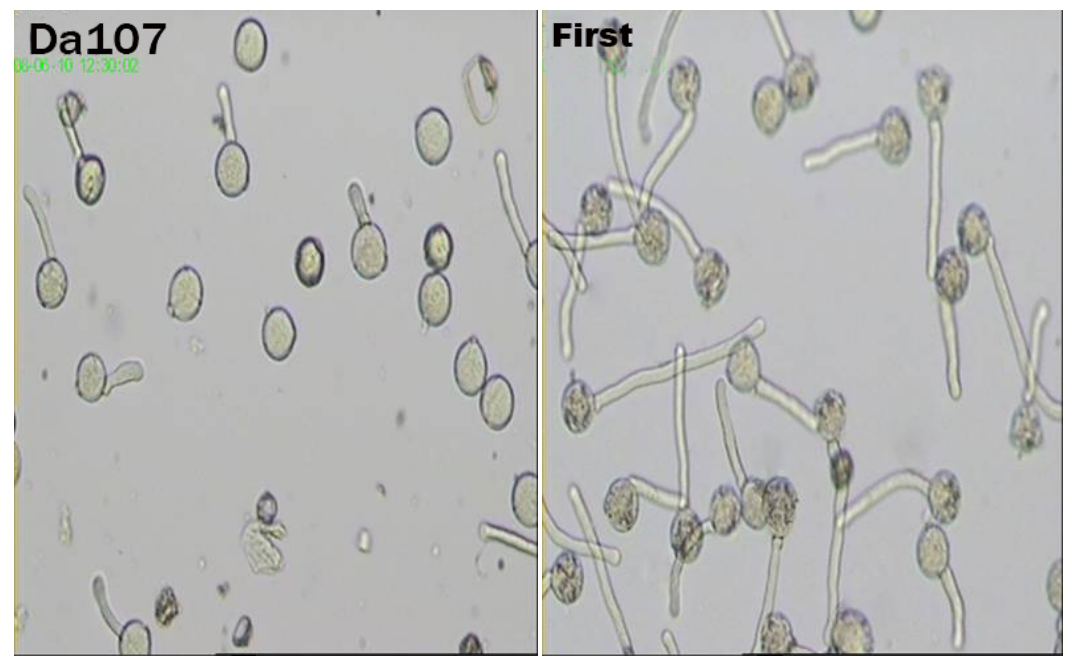

Figure 2. The comparison chart of PGR [planted at $20^{\circ} \mathrm{C}-28^{\circ} \mathrm{C}(\mathrm{NT})$ ].

major factor affecting the PGR of Da107.

The PGR of Da107 was low to $4.34 \%$ at $26.43^{\circ} \mathrm{C}$ night temperature, but up to $56.21 \%$ at $16.42^{\circ} \mathrm{C}$. It can be seen that correlation coefficient between PGR and temperature was -0.97 (Table 1). It meant that RGR of Da107 was significantly negatively related to temperature. With the increase of temperature, the PGR of Da107 was decreased. The PGR of 56.21\% of Da107 had no significant difference with First when the temperature was $16.42^{\circ} \mathrm{C}$. In other words, Da107 restored fertility under the conditions of low temperature. The T-4 mutant plant's PGR was four times higher in autumn (low temperature) than that in spring (high temperature) and it was restored when exposed to low temperatures [10]. Masaharu Masuda reported that the fertility of T-4 mutant type was affected by night temperature and the male-sterile line which restored fertility could be propagated under low night temperature conditions (above $12^{\circ} \mathrm{C}$ and below $18^{\circ} \mathrm{C}$ ) [11]. SPSS analysis test showed that the analysis of variance at $1 \%$ level of significance indicated that the differences of the PGR between Da107 and the control first were statistically significant. So the results manifested that with the environment conditions changed, Da107 was a perfect MSL whose sterility was up to $95 \%$ and maintenance line also.

\subsection{The Floral Organ}

Normal fertile line First (Figure 3.3) showed big corolla, full-fledged filament, full stylus and yellow plump 
anther, and tetradynamous stamen was as high as or slightly higher than the stylus. Compared with the First, small coralla, browning or whiting thin less anther, and tetradynamous stamen much higher than the stylus was characterized as Da107 (Figure 3.1 vs Figure 3.2).

In natural conditions, that the length of Da107's stylus was about 75\% longer than the stamen (Table 2) posed an obstacle to self-pollination, and the trait stood for a functional male sterile phenotype (FMSP) [12]. So Da107 was a double male sterility line. In other words, Da107 was not only the thermo-sensitivity male-sterile mentioned above, but also FMSP. Studies on the genetic variability of exserted stigma-sterility showed that this male-sterile was not to be evaluated based only on the length of the style that protruded from the anther cone, but also depended on the length of both style and anther, and all these were affected mainly by the temperature [13] [14]). The length of the stylus and stamen increased with the temperature rising. That was to say, the sterility of Da107 increased with temperature rising. It could be concluded that Da107 was a perfect male sterile line under the condition of higher temperature. Furthermore, Da107's stylus had the diameter almost one bigger than First's (Table 2), which was in favor of the hand pollination immensely. In any case, Da107 was used as MSL at high temperature or maintenance line at low temperature

\section{3. $F_{1}$ Seeds Contamination}

Table 3 showed that the $\mathrm{F}_{1}$ hybrid-seed contamination rate with the selfed-seed was inapparent, so, Da107 was a valuable sterile material for breeding when taken as female parent.

\section{Conclusion}

The new type MSL Da107 characterized with pollen temperature-sensitivity and stigma exsertion can be used as

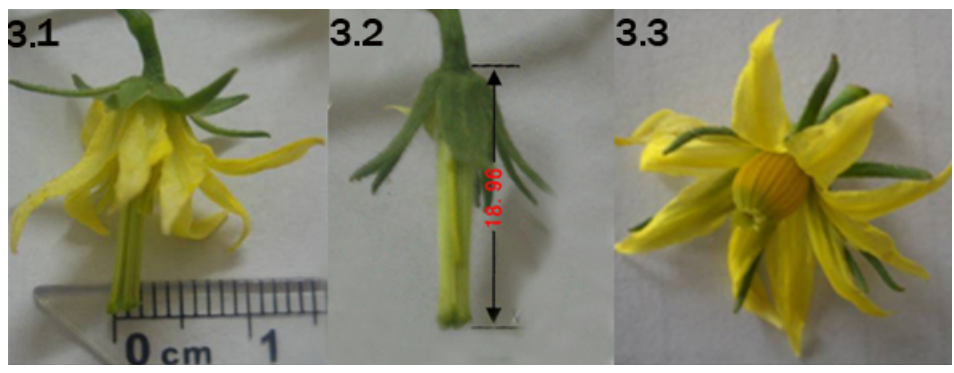

Figure 3. The comparison charts of about floral organs of da107 (3.1 vs 3.2) and first (3.3).

Table 1. Correlation analysis of the pollen germination rate at different temperatures.

\begin{tabular}{cccccc}
\hline Period (month/day) & Average night temperature $\left({ }^{\circ} \mathrm{C}\right)$ & PGR of Da107 (\%) & error & PGR of first (\%) & Error \\
\hline 8/7 - 8/9 & 26.43 & 4.34 & 0.95 & 67.45 & 1.65 \\
$10 / 5-10 / 7$ & 25.91 & 11.06 & 0.9 & 79.12 & 1.79 \\
$2 / 11-2 / 13$ & 23.05 & 33.61 & 1.65 & 68.70 & 1.07 \\
$12 / 9-12 / 11$ & 16.42 & 56.21 & 2.41 & 65.60 & 1.68 \\
$\quad$ Correlation coefficient with temperature & & $-0.97^{* *}$ & & 0.56 & \\
\hline
\end{tabular}

${ }^{* *}$ Significant at 0.01 probability level.

Table 2. Correlation analysis of floral organ at different temperature.

\begin{tabular}{|c|c|c|c|c|c|c|}
\hline $\begin{array}{c}\text { Period } \\
\text { (month/day) }\end{array}$ & $\begin{array}{l}\text { Night average } \\
\text { temperature }\left({ }^{\circ} \mathrm{C}\right)\end{array}$ & $\begin{array}{l}\text { Length of } \\
\text { stylus (mm) }\end{array}$ & $\begin{array}{c}\text { Length of } \\
\text { stamen (mm) }\end{array}$ & $\begin{array}{c}\text { Difference of stylus } \\
\text { and stamen (mm) }\end{array}$ & $\begin{array}{l}\text { Stylus diameter } \\
\text { (Da107) (mm) }\end{array}$ & $\begin{array}{l}\text { Stylus diameter (first) } \\
\text { (mm) }\end{array}$ \\
\hline $9 / 24-9 / 28$ & $27.9 \pm 0.3$ & 20.33 & 12.37 & 7.96 & 2.31 & 1.37 \\
\hline $10 / 15-10 / 19$ & $24.9 \pm 0.3$ & 18.85 & 11.86 & 6.99 & 2.27 & 1.11 \\
\hline $12 / 10-12 / 14$ & $17.9 \pm 0.4$ & 17.17 & 11.13 & 6.04 & 2.13 & 1.01 \\
\hline $1 / 6-1 / 9$ & $9.38 \pm 0.12$ & 15.85 & 9.86 & 5.99 & 1.95 & 0.97 \\
\hline \multicolumn{2}{|c|}{ Correlation coefficient with temperature } & $0.98^{* *}$ & $0.99^{* *}$ & $0.88^{* *}$ & $1.00^{* *}$ & $0.84^{* *}$ \\
\hline
\end{tabular}


Table 3. Rate of $F_{1}$ seeds contamination in different male parents cross combinations, whose female parent was Da107.

\begin{tabular}{cccc}
\hline Cross combination & No. of trial seedlings (a) & No. of selfed-seedlings (b) & Contamination rate $(\mathrm{b} / \mathrm{a} \times 100)$ \\
\hline Da107 $\times$ Dongsheng & 430 & 3 & 0.6977 \\
Da107 $\times 12$ & 562 & 7 & 1.6279 \\
Da107 $\times$ Niufanqie & 624 & 16 & 3.7209 \\
Da107 $\times$ A3 & 437 & 12 & 2.7907 \\
\hline
\end{tabular}

fertility line in autumn (low temperature), and the hybrid seeds are produced by the hybridization with maintenance line in the way of artificial pollination in spring. What's more, the length of Da107's stylus was much longer than that of another, which ensured the purity of the hybrid seeds. Meanwhile, Da107, leaving a perfect male-sterile trait, overcame the problems associated with the labor-intensive process for emasculation during hybrid-seed production.

\section{Funding}

The national ministry of science and technology and international cooperation funding project (2006DFA33380); funding project of Guilin comprehensive experimental station, national commodity vegetable industry technology system (CARS-25-X-XX).

\section{References}

[1] Kilchevsky, A. and Dobrodkin, M. (2000) Use of Functional Male Sterility in Seed Production of Tomato Hybrids. Acta Physiologiae Plantarum, 22, 232-234. http://dx.doi.org/10.1007/s11738-000-0018-1

[2] Masuda, M., Uchida, K., Kato, K. and Agong, S.G. (1999) Characterization and Genetic Analysis of Male Sterile Mutant Induced in Tomato cv. First, Having Mature Pollen Stainable with Acetocarmine. Journal of the Japanese Society for Horticultural Science, 68, 566-568. http://dx.doi.org/10.2503/jjshs.68.566

[3] Gorman, S.W. and McCormick, S. (1997) Male Sterility in Tomato. Critical Reviews in Plant Sciences, 161, 31-53. http://dx.doi.org/10.1080/713608142

[4] Zhu, G.-M., Li, J.F. and Li, P. (1982) A Preliminary Investigation on Morphological and Anatomical Characters of Sterile Flowers in Tomato (Lycopersicon esculentum Mill.). Transactions on Journal of Northeast Agricultural College, 2, 46-52.

[5] Chen, L., Tan, L.L. and Wang, Y. (2009) Preliminary Study on Physiological Mechanism of Temperature Sensitive Male Sterile Tomato. Transactions on Journal of Northeast Agricultural College, 1, 31-35.

[6] Yan Z.-M. (2010) Analysis of ESTs Related to Temperature Sensitivity of Longstigma Mutant Tomato T431 and the Preliminary Analysis of LeMBF1 in the Flower Bud Differentiation. Thesis, Northest Agricultural University, Harbin.

[7] Wang, X.-Y., Liang, C.-Y. and Deng, L.-F. (2011) Studies on Physiological and Biochemical Characters in ThermoSensitive Male Sterile Line Tomato Solanum lycopersicum L. T-4. Transactions on Northern Horticulture, 15, 29-31.

[8] Guo, Y.-H., Yu F.-D. and Gan, G.-Y. (2013) Studies on Protein Content, POD and EST Isozyme of Thermo-Sensitive Genic Male-Sterile Tomato T-4. Transactions on China Vegetable, 6, 58-62.

[9] Georgiev, H. (1991) Heterosis in Tomato Breeding. In: Kalloo, G., Ed., Genetic Improvement of Tomato, Monographs on Theoretical and Applied Genetics, Springer-Verlag, Berlin, 83-98.

[10] Masuda, M., Uchida, K., Kato, K. and Agong, S.G. (2000) Restoration of Male Fertility in Seasonally Dependent Male Sterile Mutant Tomato, Lycopersicon esculentum cv. First. Journal of the Japanese Society for Horticultural Science, 69, 557-562. http://dx.doi.org/10.2503/jjshs.69.557

[11] Masuda, M., Kato, K., Murakami, K., Nakamura, H., Ojiewo, C.O. and Masinde, P.W. (2007) Partial Fertility Restoration as Affected by Night Temperature in a Male-Sterile T-4 Mutant Tomato, Lycopersicon esculentum L. Journal of the Japanese Society for Horticultural Science, 76, 41-46. http://dx.doi.org/10.2503/jjshs.76.41

[12] Rick, C.M. and Robinson, J. (1951) Inherited Defects of Floral Structure Affecting Fruitfulness in Lycopersicon esculenturn. American Journal of Botany, 38, 639-652. http://dx.doi.org/10.2307/2437776

[13] Takhur, M.R, (1970) Environmental and Genetic Control of Heterostyly in Tomato (Lycopersicon esculentum Mill.). Dissertation, The Ohio State University, Columbus.

[14] Bistra, A. (2000) Functional Male Sterility in Tomato (Lycopersicon esculentum Mill.) and Its Application in Hybrid Seed Production. Acta Physiologiae Plantarum, 22, 221-225. http://dx.doi.org/10.1007/s11738-000-0015-4 